\title{
Preference for wheat straw by lambs conditioned with intraruminal infusions of starch
}

\author{
BY JUAN J. VILLALBA AND FREDERICK D. PROVENZA \\ Department of Rangeland Resources, Utah State University, Logan, Utah, USA 84322-5230
}

(Received 29 January 1996-Revised 1 April 1996-Accepted 16 April 1996)

\begin{abstract}
We hypothesized that feed preference depends on the interplay between flavour and postingestive effects, and we tested two predictions based on this hypothesis: (1) lambs acquire preferences for poorly nutritious feeds paired with starch; and (2) preferences persist when starch is no longer administered. Twenty lambs were randomly allocated to two groups and conditioned as follows: on odd-numbered days, lambs in group 1 received onion-flavoured wheat straw and lambs in group 2 received oregano-flavoured wheat straw. On even-numbered days, the flavours were switched and starch (2.5-9.4\% of the digestible energy received/d) was infused into the rumen of all animals during straw consumption. Four periods of $8 \mathrm{~d}$ of conditioning were performed and on the 9th day of each period all animals were offered a choice between onion- and oregano-flavoured straw. After conditioning, starch administration was suspended and lambs were offered onion- and oreganoflavoured straw at weekly intervals for 8 weeks (extinction). Lambs strongly preferred the flavoured straw paired with starch, and this preference persisted during extinction. Thus, these results suggest that the postingestive effects of energy play an important role in the development of feed preferences of ruminants.
\end{abstract}

Palatability: Starch: Feed preference: Hedonic-shift: Flavour

It is not completely understood why ruminants manifest preferences for feeds. On the one hand, preferences have been attributed to flavour, which provides hedonic sensations associated with eating (reviewed by Grovum, 1988). On the other hand, nutrients have been proposed as a reason for feed selection (Westoby, 1978), and toxins as a reason for feed avoidance (Freeland \& Janzen, 1974). According to these hypotheses, flavour and the postingestive effects of nutrients and toxins are autonomous phenomena, and the former is usually considered to influence preference more than the latter. Nevertheless, the two phenomena may be related: postingestive feedback from nutrients and toxins may influence flavour preferences (Provenza, 1995a).

The postingestive effects of energy cause non-ruminants to acquire preferences for non-nutritive flavours (Sclafani \& Nissenbaum, 1988; Perez et al. 1995), and the preferences persist when energy is no longer administered. Thus, animals apparently acquire a liking for flavours previously associated with energy (Mehiel, 1991; Sclafani, 1991). The energy content of the feed may also be important in the development of preferences in ruminants because energy is vital for survival, growth, and productivity (Church, 1988). For example, sheep prefer non-nutritive flavours paired with glucose to non-nutritive flavours paired with saccharin or water (Burritt \& Provenza, 1992; Ralphs et al. 1995). In these studies glucose provided $26-46 \%$ of the total daily energy intake of the animals. Thus, it is not known if sheep form preferences for feeds containing little energy or if these preferences persist after conditioning. 
Accordingly, the objectives of the present study were to determine: (1) if lambs form a preference for a low-quality feed (wheat straw) consumed with intraruminal infusions of low amounts of starch, and (2) if the preference persists when feed ingestion is no longer paired with starch.

\section{MATERIALS AND METHODS}

\section{Before conditioning}

Twenty Rambouillet-Columbia-Finn-Targhee crossbred wethers weighing 26 (SEM 0.7) $\mathrm{kg}$ were randomly allocated to two groups (ten animals in each group) and penned individually at the Green Canyon Ecology Center, Utah State University, Logan, Utah. Before conditioning, and on even days, group 1 was offered oregano-flavoured straw (10$20 \mathrm{~mm}$ particle size) and group 2 was offered onion-flavoured straw. On odd days straw was offered to all animals again but the flavours were switched: group 1 was given onionflavoured straw and group 2 was given oregano-flavoured straw. The straw was flavoured by mixing $20 \mathrm{~g}$ dried, ground onion (or oregano) powder (Pacific Foods, Washington, USA) with each $\mathrm{kg}$ wheat straw. Lambs were exposed to the flavoured straw from 08.00 to 12.00 hours, during $12 \mathrm{~d}$. At 12.00 hours intake of the straw was recorded and lucerne (Medicago sativa) pellets were given.

\section{Conditioning}

On even days lambs in group 1 were offered oregano-fiavoured straw and lambs in group 2 were offered onion-flavoured straw at 08.00 hours. Immediately after beginning to eat straw, lambs in both groups were given a starch suspension by oral intubation (treatment 1). The starch suspension was prepared using $250 \mathrm{ml}$ tap water at room temperature. On odd days flavours were switched so that lambs in group 1 received onion-flavoured straw and lambs in group 2 received oregano-flavoured straw, but no starch suspension was given (treatment 2); instead only the tube used for the administration (on even days) was introduced for a few seconds in each lamb's throat immediately after it started eating. On all days refusals were collected and weighed at noon and lucerne pellets were offered. Eight days (four odd- and four even-numbered days) of conditioning formed one conditioning period.

Offering two distinctive flavours with or without starch controlled for possible flavour effects. The amount of straw offered on even days was equal to a lamb's intake of straw the previous day, which controlled for exposure to the flavoured straw. Lambs consumed 59 (SEM 4.3) g/d when flavoured straw was not paired with starch and 65 (SEM 4.3) g/d when flavoured straw was paired with starch. Switching flavours every other day and providing starch at the same time on the same day controlled for possible differences that the administration of energy might have induced in the rumen of different groups of animals.

Our objectives were to determine the effect of low doses of starch on flavour preference by lambs, and if preferences were acquired, to determine their persistence when starch was no longer administered (extinction). However, we did not know the minimum threshold for starch detection by sheep, so we began infusing low doses of starch and we gradually increased the amount of starch infused into sheep during conditioning. The level of starch was increased by $5 \mathrm{~g}$ every even day, beginning at $20 \mathrm{~g}$ and ending at $75 \mathrm{~g}$. There were four periods of conditioning with starch: period 1 ( 20 to $35 \mathrm{~g}$ ); period 2 (40 to $55 \mathrm{~g}$ ); period 3 (60 to $75 \mathrm{~g}$ ); and period 4 (75 g) (Table 1). The amounts of starch administered 
Table 1. Amounts of starch $(g)$ infused into sheep during four periods of conditioning of 8 days each

\begin{tabular}{lcccccccc}
\hline \hline & \multicolumn{7}{c}{ Day within period } \\
\cline { 2 - 9 } Conditioning period & 1 & 2 & 3 & 4 & 5 & 6 & 7 & 8 \\
\hline 1 & - & 20 & - & 25 & - & 30 & - & 35 \\
2 & - & 40 & - & 45 & - & 50 & - & 55 \\
3 & - & 60 & - & 65 & - & 70 & - & 75 \\
4 & - & 75 & - & 75 & - & 75 & - & 75 \\
\hline \hline
\end{tabular}

ranged from $2.5 \%(13.40 \mathrm{~kJ} / \mathrm{kg}$ body weight (BW)) to $9.4 \%(42.14 \mathrm{~kJ} / \mathrm{kg} \mathrm{BW})$ of the total digestible energy (DE) offered (National Research Council, 1985); the amount increased by $3.35 \mathrm{~kJ} / \mathrm{kg} \mathrm{BW}$ each even day. Lucerne pellets plus straw and starch provided $80 \%$ of the DE requirement of the lambs. Lucerne intake ranged from 1130 to $1170 \mathrm{~g} / \mathrm{d}$, depending on starch administration and body weight. At the end of conditioning, lambs weighed 31 (SEM 0.7) kg.

\section{Preference tests}

After each $8 \mathrm{~d}$ conditioning period, lambs received oregano- and onion-flavoured straw simultaneously for $20 \mathrm{~min}$, and intake of each feed was measured.

\section{Extinction tests}

After completing the four conditioning periods, all lambs received lucerne pellets $a d$ libitum every day. Once weekly for 8 weeks at 08.00 hours, lambs were offered oreganoand onion-flavoured straw for 20 min without administration of starch.

\section{Ruminal determinations}

An additional group of four lambs received the same diets and conditioning schedule described previously. Samples of rumen fluid were obtained through a stomach tube before and every hour for $3 \mathrm{~h}$ after starch was administered. The amount of starch administered was $0 \mathrm{~g}$ (corresponding to odd days), and the maximum amount administered during each conditioning period: 35,55 , and $75 \mathrm{~g}$ (Table 1 ). Ruminal $\mathrm{pH}$ was measured and samples $(18 \mathrm{ml})$ of rumen contents were mixed with $2 \mathrm{ml} 6 \mathrm{M}-\mathrm{HCl}$, centrifuged and prepared for volatile fatty acid (VFA) determinations (Wiedmeier et al. 1987).

\section{Statistical analyses}

Feed intake during preference tests was analysed as a split-plot design with animals nested within groups. Group ( 1 or 2) was the between-subject factor; treatment received during conditioning ( 1 or 2 ) and period were the within-subject factors in the split-plot. Period was the repeated measure in the analysis. Values for $\mathrm{pH}$ and VFA were analysed in a split-plot design with lambs and amount of starch as the whole plot, and time of rumen fluid extraction as the sub-plot. 


\section{RESULTS}

\section{Before conditioning}

During the $12 \mathrm{~d}$ adaptation period there were no differences in straw intake between groups (22 v. $26 \mathrm{~g}$; SEM $3.9 \mathrm{~g} ; P>0.05$ ), but lambs preferred oregano- to onion-flavoured straw (29 v. 20 g; SEM 3.9 g; $P<0.05$ ) (Fig. 1). Intake was low (24 (SEM 2.7) g) and variable throughout the adaptation period and some animals refused nearly all the straw. For example, for the last $4 \mathrm{~d}$, seven animals ate $<5 \mathrm{~g}$ of straw (range $0-4 \mathrm{~g}$ ).

\section{Preference tests}

Lambs strongly preferred the flavoured straw paired with starch $(63 v .17 \mathrm{~g}$; SEM $5.1 \mathrm{~g}$; $P<0.001$ ), and reduced their preference for the other flavour, as indicated by a treatment $\times$ day interaction $(P<0.001)$. This pattem was evident during the first conditioning period $(P<0.001)$, and became more apparent throughout conditioning (Fig. 2).

Onion- and oregano-flavoured straw were consumed in similar amounts during preference tests (44 v. $35 \mathrm{~g}$ respectively, SEM $5.1 \mathrm{~g} ; P>0.05$ ). Preference for onionflavoured straw increased by $76 \%$ (from 17 to $72 \mathrm{~g} / 20 \mathrm{~min} ; \mathrm{SEM} 7.2 \mathrm{~g} ; P<0.001$ ), whereas preference for oregano-flavoured straw increased by $71 \%$ (from 16 to $55 \mathrm{~g} / 20 \mathrm{~min}$; SEM $7.2 \mathrm{~g} ; P<0.001$ ) when these flavours were associated with starch.

\section{Extinction tests}

Lambs preferred the flavours paired with starch even after starch was no longer administered ( 71 v. $21 \mathrm{~g}$, SEM $6.3 \mathrm{~g} ; P<0.001$ ), and intake of straw containing those flavours remained relatively constant throughout extinction tests (Fig. 3). In contrast, as the levels of starch and amount of exposure increased during conditioning, so did lambs' preferences for the flavours associated with starch. The lack of further increase in preferences for flavours paired with starch during extinction $(P>0.05)$, despite increased

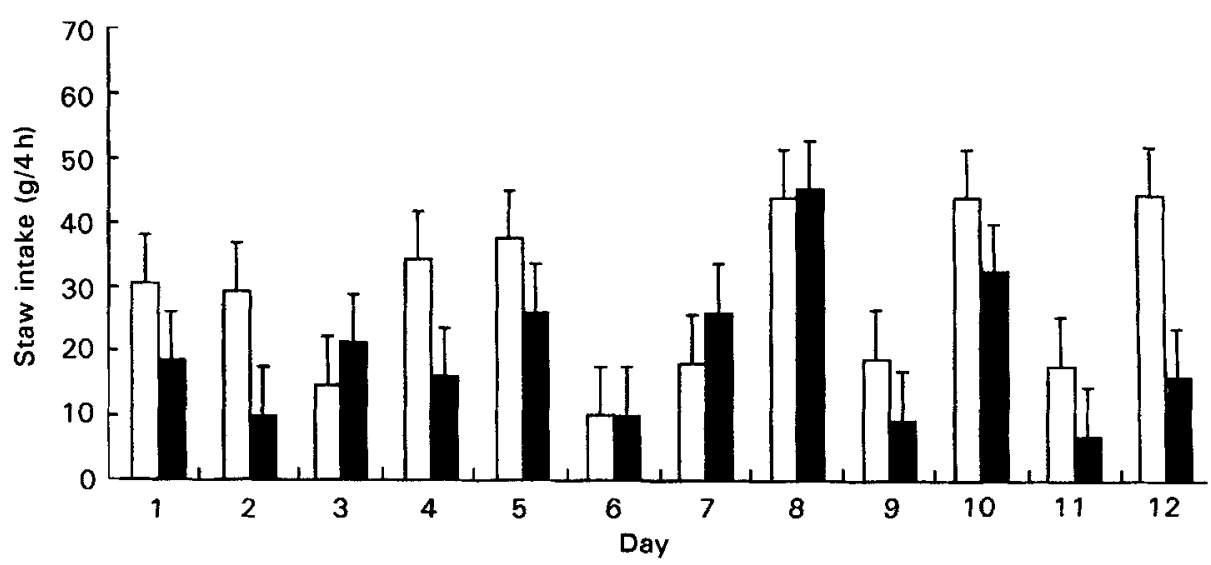

Fig. 1. Intake by lambs of straw flavoured with oregano $(\square)$ or onion ( $\square$ ) during the adaptation period. Values are means for ten animals, with their standard errors represented by vertical bars. 


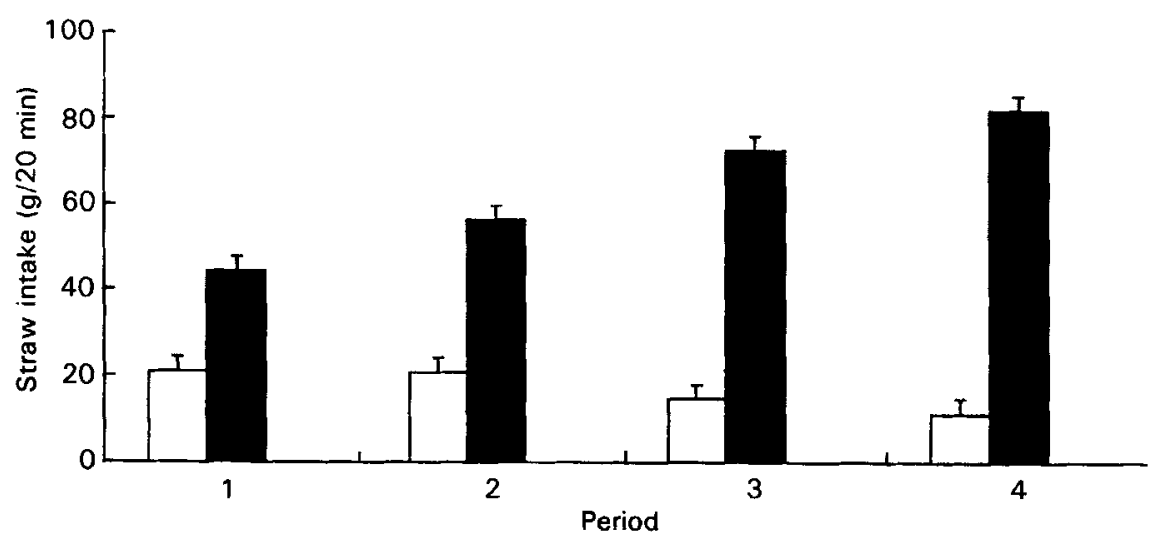

Fig. 2. Intake of flavoured straw by lambs during four preference tests, each conducted after an $8 \mathrm{~d}$ period of starch conditioning. ( $\square$ ), No starch; $(\mathbf{C})$, starch given by oral administration. Values are means for ten animals, with their standard errors represented by vertical bars.

exposure to the flavours during this period, suggests that the amount of energy affected preference more than did the duration of exposure during conditioning.

Lambs preferred onion to oregano during extinction tests $(60$ v. $32 \mathrm{~g}$; SEM $8.8 \mathrm{~g}$; $P<0.001$ ). There was a slight increase in intake of the flavours not paired with starch near the end of the experiment (Fig. 3), as reflected in a treatment $\times$ day interaction $(P<0.001)$.

\section{Ruminal determinations}

Level of starch did not affect ruminal $\mathrm{pH}(P>0.05)$ (Fig. 4). VFA levels for days when starch was administered and when starch was not administered are shown in Table 2. All levels of starch delivered increased the molar concentrations of acetic, propionic, and butyric acids $(P<0.001)$ in comparison with $0 \mathrm{~g}$ starch administration (level corresponding to odd days) and there was a treatment $\times$ time interaction for all major VFA $(P<0.05)$.

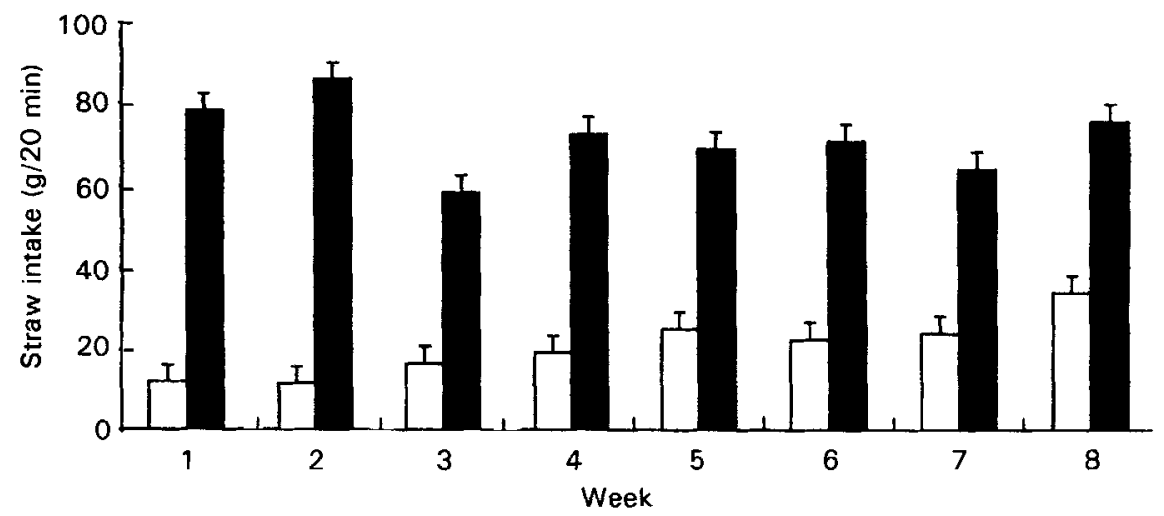

Fig. 3. Intake of flavoured straw by lambs after cessation of starch conditioning (extinction). ( $\square$ ), Flavour associated with no starch; ( $\square$, flavour associated with starch. Values are means for ten animals, with their standard errors represented by vertical bars. 


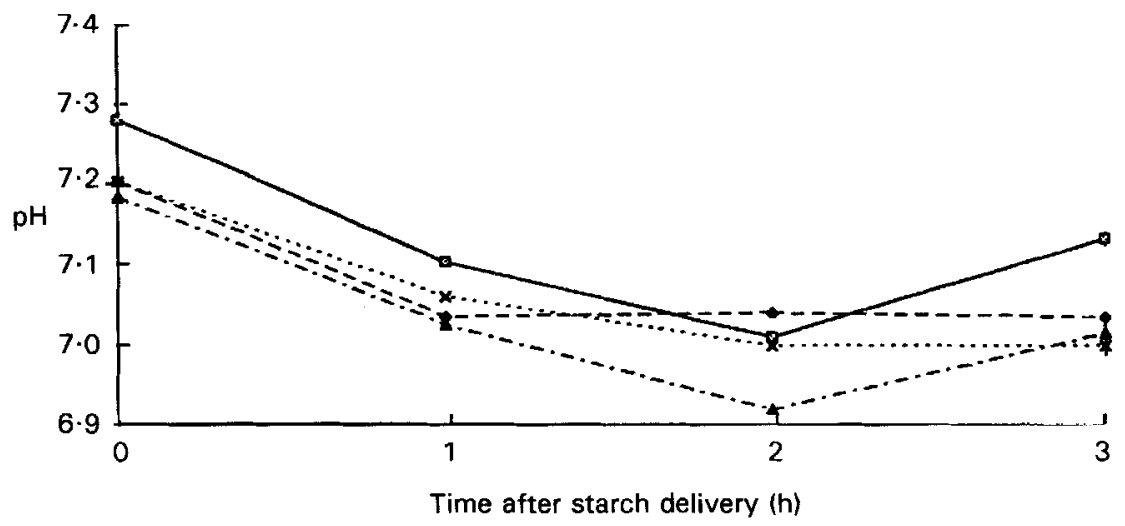

Fig. 4. $\mathrm{pH}$ values in rumen fluid of four lambs before and $3 \mathrm{~h}$ after intraruminal administrations of $0,(-\bullet-) ; 35,(-\square-)$; $55,\left(-\Delta_{-}\right)$and $75 \mathrm{~g}(-\times-)$ of starch (SEM 0.03). For details of procedures, see pp. 288-289.

Table 2. Levels of volatile fatty acids (VFA) (mmol/l) in rumen contents of four lambs before and after intraruminal administrations of $0,35,55$, and $75 \mathrm{~g}$ of starch

(Mean values with their pooled standard error)

\begin{tabular}{|c|c|c|c|c|c|c|}
\hline \multirow[b]{2}{*}{ VFA } & \multirow{2}{*}{$\begin{array}{l}\text { Starch level } \\
\text { (g) }\end{array}$} & \multicolumn{4}{|c|}{ Time after starch delivery (h) } & \multirow[b]{2}{*}{ SEM } \\
\hline & & 0 & 1 & 2 & 3 & \\
\hline Acetate & $\begin{array}{r}0 \\
35 \\
55 \\
75\end{array}$ & $\begin{array}{l}36 \cdot 24 \\
47 \cdot 00 \\
53 \cdot 24 \\
48.94\end{array}$ & $\begin{array}{l}29.66 \\
40 \cdot 14 \\
57.00 \\
46.72\end{array}$ & $\begin{array}{l}29.64 \\
45.04 \\
48.64 \\
38.52\end{array}$ & $\begin{array}{l}36.48 \\
30.05 \\
45 \cdot 10 \\
43.43\end{array}$ & 2.59 \\
\hline Propionate & $\begin{array}{r}0 \\
35 \\
55 \\
75\end{array}$ & $\begin{array}{l}7.36 \\
8.37 \\
9.34 \\
8.58\end{array}$ & $\begin{array}{l}5.64 \\
7.02 \\
9.95 \\
8.45\end{array}$ & $\begin{array}{l}5.62 \\
7.68 \\
8.60 \\
6.92\end{array}$ & $\begin{array}{l}6.57 \\
5.24 \\
8.46 \\
7.59\end{array}$ & 0.44 \\
\hline Butyrate & $\begin{array}{r}0 \\
35 \\
55 \\
75\end{array}$ & $\begin{array}{l}4.30 \\
5.50 \\
5.99 \\
5.30\end{array}$ & $\begin{array}{l}3 \cdot 22 \\
4.74 \\
6 \cdot 64 \\
5 \cdot 81\end{array}$ & $\begin{array}{l}3.17 \\
5.65 \\
6.34 \\
5.61\end{array}$ & $\begin{array}{l}3.70 \\
4.05 \\
6.56 \\
6.38\end{array}$ & 0.31 \\
\hline Isobutyrate & $\begin{array}{r}0 \\
35 \\
55 \\
75\end{array}$ & $\begin{array}{l}0.91 \\
1.11 \\
0.99 \\
1.32\end{array}$ & $\begin{array}{l}0.66 \\
0.80 \\
1.00 \\
1.06\end{array}$ & $\begin{array}{l}0.69 \\
0.88 \\
0.81 \\
0.86\end{array}$ & $\begin{array}{l}0-86 \\
0-67 \\
0-91 \\
1-02\end{array}$ & 0.08 \\
\hline Isovalerate & $\begin{array}{r}0 \\
35 \\
55 \\
75\end{array}$ & $\begin{array}{l}1.42 \\
1.68 \\
1.56 \\
1.96\end{array}$ & $\begin{array}{l}1.02 \\
1.21 \\
1.45 \\
1.52\end{array}$ & $\begin{array}{l}1.01 \\
1.30 \\
1.23 \\
1.21\end{array}$ & $\begin{array}{l}1.28 \\
0.97 \\
1.19 \\
1.40\end{array}$ & $0 \cdot 10$ \\
\hline Valerate & $\begin{array}{r}0 \\
35 \\
55 \\
75\end{array}$ & $\begin{array}{l}0.66 \\
0.69 \\
0.86 \\
0.82\end{array}$ & $\begin{array}{l}0.48 \\
0.54 \\
0.77 \\
0.69\end{array}$ & $\begin{array}{l}0.44 \\
0.51 \\
0.65 \\
0.54\end{array}$ & $\begin{array}{l}0.53 \\
0.35 \\
0.56 \\
0.60\end{array}$ & 0.04 \\
\hline
\end{tabular}


Valerate levels increased after 55 and $75 \mathrm{~g}$ starch compared with no starch administration $(P<0.05)$ and there was no treatment $\times$ time interaction $(P>0.05)$.

\section{DISCUSSION}

\section{Before conditioning}

Straw intake was low (only $24 \mathrm{~g}$ in $4 \mathrm{~h} / \mathrm{d}$ during $12 \mathrm{~d}$ ) and variable during adaptation (Fig. 1), but after only four pairings with starch (period 1), intake increased to $66 \mathrm{~g}$ during $20 \mathrm{~min}$. The increase in intake can be interpreted as an enhanced incentive or drive to eat flavoured straw due to its association with intraruminal infusions of a readily available source of energy (starch) during conditioning. Greenhalgh \& Reid (1971) also found that sheep were reluctant to eat straw, but intake increased when grass hay (a more nutritious feedstuff) was put into the rumen as sheep ate the straw. In the present study, lambs ate straw readily following the delivery of starch into the rumen, and their intake increased immediately during the first period of conditioning. Thus, lack of nutrient feedback from the gut, and not ruminal limitations, apparently affected intake in both studies (Provenza, 1995b).

\section{Preference tests}

Herbivores select diets containing required nutrients and avoid those that are non-nutritive or toxic (Provenza, 1995a). The mechanism that probably underlies this nutritional wisdom is the ability of animals to learn through the post-ingestive consequences that nutrients and toxins elicit in the gastrointestinal tract and in the brain, such that preference for the taste of a feed is adjusted according to the feed's effects on the internal environment (Cabanac, 1971; Leibowitz, 1988; Gibson \& Booth, 1989; Mehiel, 1991; Sclafani, 1991; Provenza, $1995 a, b)$.

This hypothesis has not been unanimously accepted, primarily due to a lack of any experimental analysis, and thus the ability of herbivores to acquire preferences for feeds based on post-ingestive effects of nutrients has been questioned (e.g. Coppock et al. 1974; Zahorik \& Houpt, 1977). Indeed, the ability of herbivores to learn preferences based on nutrient feedback is thought to be of less significance than their ability to develop aversions to toxins (Cassini, 1994). This argument has grown from the misconception that ingesting needed nutrients is less critical than avoiding toxins. Nevertheless, sheep form strong preferences for non-nutritive flavours paired with glucose when glucose provides a high percentage (i.e. 26-46\%) of their daily energy intake (Burritt \& Provenza, 1992; Ralphs et al. 1995), and we have now demonstrated that sheep acquire preferences at much lower levels of energy (2.5-9.4\%). Furthermore, our results show that lambs formed strong preferences for flavours after as few as four pairings with small amounts (i.e. $35 \mathrm{~g}$ ) of starch (Fig. 2), and brief exposures to straw.

This implies that acquiring preferences for feeds that provide readily available energy is as important as developing aversions to toxic feeds. This should not be surprising given the importance of energy in feed intake (Baile, 1971; Baile \& McLaughlin, 1979; Anil \& Forbes, 1980; Anil et al. 1993). Considering the low and variable nutritional quality of the forages ruminants typically encounter, it would be surprising if they had not evolved flavour-feedback mechanisms capable of discriminating subtle differences in energy content of feeds. 
Preference for particular nutrients depends on nutritional needs (Booth \& Toase, 1983; Booth, 1985; Mook, 1988). Preference increases when nutrients ameliorate needs, and decreases when they satiate needs (Provenza, 1995a,b). In the present study lambs ingested only $80 \%$ of their required DE, which may have enhanced their sensitivity to energy, and consequently strengthened the development of their feed preferences. Learned preferences for energy are strongest when rats are feed-deprived (Capaldi, 1990; Mehiel, 1991). Conversely, eating to satiety can be mildly-to-strongly aversive depending on the concentration and rate of nutrient delivery into the gastrointestinal tract (Provenza, 1996a). Thus, feed preferences are more likely to be conditioned when the concentration of nutrients and their rate of delivery are below satiety. In the present study starch provided less than $10 \%$ of the DE consumed per day by lambs. Higher levels of nutrients may condition feed aversions. For example, high levels of propionate in the rumen or portal vein depress feed intake, apparently due to development of aversions (Farningham \& Whyte, 1993; Ralphs et al. 1995).

Feed ingestion based on needs may also explain why lambs invariably eat a lowenergy feed after initially preferring one of higher quality (Provenza et al. 1996). For instance, lambs consume lower levels of energy (starch) after receiving a high-energy diet (oat grain), whereas lambs that have ingested a meal high in protein (soyabean meal) prefer energy (Villalba \& Provenza, unpublished results). The previous ingestion of grain probably leads to an avoidance of the additional energy supplied by starch and to an opposite response when soyabean meal is ingested. Thus, lambs fed on a ration high in energy subsequently prefer feed lower in energy (and higher in protein); whereas those fed on a ration high in protein subsequently prefer feed higher in energy (Wang \& Provenza, 1996). Feed deprivation leads to the release of noradrenaline which stimulates appetite for carbohydrates in rats; consumption of carbohydrate-rich feeds by rats is then followed by a depression in noradrenaline release and an enhancement in serotonin production in the medial hypothalamus, which apparently promotes an avoidance of carbohydrates and a preference for protein (Wurtman \& Wurtman, 1986; Leibowitz, 1988).

An alternative explanation for avoidance responses is that rapid increases in rumen osmolality (e.g. promoted by concentrate feeds) can lead to significant reductions in feed intake and preference, which would minimize further deviations from optimal rumen conditions (Cooper et al. 1995). According to this theory, feed preferences are also more likely to develop when the supply of nutrients (e.g. in rate or dose) is below a threshold for promoting abrupt changes of osmolality in the rumen.

\section{Extinction tests}

Lambs continued to prefer the flavour paired with starch, even 2 months after they ceased to receive starch (Fig. 3). Rats also retain learned preferences, even for bitter and sour tastes, that they initially avoid (Mehiel, 1991; Sclafani, 1991). Collectively, these results suggest that readily available energy, as provided by starch, increases the hedonic value of flavoured feeds such that preferences persist, even after cessation of starch administration, and become resistant to extinction.

During adaptation animals preferred oregano- to onion-flavoured straw, but this pattern was reversed during the extinction tests. Phenolics (Kikuzaki \& Nakatani, 1989), glucopyranosides (Nakatani \& Kikuzaki, 1987) and oils (Salmeron et al. 1990) in oregano may have caused aversive postingestive effects (Provenza, 1995a) and thereby reduced preferences for the oregano-flavoured straw toward the end of the trial, particularly at flavour concentrations of $20 \mathrm{~g} / \mathrm{kg}$. The small amount of straw eaten during the adaptation 
period evidently was not enough to induce the detrimental effects on flavour preferences observed during extinction.

\section{Ruminal determinations}

Starch increased concentrations of VFA, which may be signals associated with the acquisition of flavour preferences. For instance, lambs prefer flavours paired with intraruminal infusions of sodium propionate (Villalba \& Provenza, 1996). Propionate and even acetate may control feed intake in ruminants (Anil \& Forbes, 1980, 1987; Anil et al. 1993). Moreover, the effects of propionate, rather than its osmolality, may reduce intake (Farningham \& Whyte, 1993), and some workers speculate that there is a propionate receptor system in ruminants (Baile, 1971). In support of this, we found that propionate and not osmolality caused the acquisition of flavour preferences in lambs (Villalba \& Provenza, 1996).

\section{CONCLUSIONS}

Our results establish that the post-ingestive effects of energy, even at low concentrations and few exposures, condition feed preferences that persist when energy pairing is terminated. Thus, the idea that animals are incapable of learning flavour preferences based on nutrient feedback is no longer tenable. Nutrient (energy) feedback from the gut should be viewed as an important factor affecting feed preferences in ruminants.

Some suggest that herbivores may be unable to relate a feed with beneficial postingestive consequences because they lack the sensory abilities to assess nutrient contents of different feeds (reviewed by Cassini, 1994). The results of the present study argue against this proposition. Instead, our findings show that the post-ingestive effects of energy increased the hedonic value of a low-quality feed in a way that persisted during extinction.

Palatability is typically viewed as a 'pure' entity strictly involving hedonics (i.e. the pleasing sensory aspects of a feed). As such, palatability and physiological factors have been proposed as two separate causes governing diet selection in ruminants (Van Soest, 1994). Our results indicate that these are not separate entities. Instead, palatability is best viewed as the interaction between taste and post-ingestive feedback, which depends on an animal's physiological condition relative to a feed's chemical characteristics (Provenza, 1996b). Accordingly, taste and post-ingestive feedback are integrated, sensed by an animal as a compound stimulus (Gibson \& Booth, 1989). Attempts to dissociate taste and feedback for single stimulus-response studies require careful experimental manipulations (e.g. Swithers \& Hall, 1994).

This research was supported by grants from the Cooperative States Research Service and the Utah Agricultural Experiment Station. This paper is published with the approval of the Director, Utah Agricultural Experiment Station, Utah State University as Journal paper number 4759. The authors gratefully acknowledge Beatriz Rodriguez for help in data collection.

\section{REFERENCES}

Anil, M. H. \& Forbes, J. M. (1980). Feeding in sheep during intraportal infusions of short-chain fatty acids and the effect of liver denervation. Journal of Physiology 298, 407-414.

Anil, M. H. \& Forbes, J. M. (1987). Neural control and neurosensory functions of the liver. Proceedings of the Nutrition Society 46, 125-133. 
Anil, M. H., Mbanya, J. N., Symonds, H. W. \& Forbes, J. M. (1993). Responses in the voluntary intake of hay or silage by lactating cows to intraruminal infusions of sodium acetate or sodium propionate, the tonicity of rumen fluid or rumen distension. British Journal of Nutrition 69, 699-712.

Baile, C. A. (1971). Metabolites as feedbacks for control of feed intake and receptor sites in goats and sheep. Physiology and Behavior 7, 819-826.

Baile, C. A. \& McLaughlin, C. L. (1979). Feed intake during volatile fatty acid injections into four gastric areas. Journal of Dairy Science 51, 1058-1063.

Booth, D. A. (1985). Food-conditioned eating preferences and aversions with interoceptive elements: conditioned appetites and satieties. In Experimental Assessments and Clinical Applications of Conditioned Food Aversions, pp. 22-41 [N. S. Braveman and P. Bronstein, editors]. New York: New York Academy of Sciences.

Booth, D. A. \& Toase, A. M. (1983). Conditioning hunger/satiety signals as well as flavour cues in dieters. Appetite 4, 235-236.

Burritt, E. A. \& Provenza, F. D. (1992). Lambs form preferences for nonnutritive flavours paired with glucose. Journal of Animal Science 70, 1133-1136.

Cabanac, M. (1971). Physiological role of pleasure. Science 173, 1103-1107.

Capaldi, E. D. (1990). Hunger and conditioned flavour preferences. In Taste, Experience and Feeding, pp. 157169 [E. D. Capaldi and T. L. Powley, editors]. Washington, DC: American Psychological Association.

Cassini, M. H. (1994). Behavioral mechanisms of selection of diet components and their ecological implications in herbivorous mammals. Journal of Mammalogy 75, 733-740.

Church, D. C. (1988). Part II: Nutrient consumption, metabolism and requirements. In The Ruminant Animal, pp. $202-448$ [D. C. Church, editor]. Englewood Cliffs: Prentice Hall.

Cooper, S. D. B., Kyriazakis, I. \& Nolan, J. V. (1995). Diet selection in sheep: the role of the rumen environment in the selection of a diet from two feeds that differ in their energy density. British Journal of Nutrition 74, 39 54.

Coppock, C. E., Everett, R. W., Smith, N. E., Slack, S. T. \& Harner, J. P. (1974). Variation in forage preference in dairy cattle. Journal of Animal Science 39, 1170-1179.

Farningham, D. A. H. \& Whyte, C. C. (1993). The role of propionate and acetate in the control of food intake in sheep. British Journal of Nutrition 70, 37-46.

Freeland, W. J. \& Janzen D. H. (1974). Strategies in herbivory by mammals: the role of plant secondary compounds. American Naturalist 108, 269-286.

Gibson, E. L. \& Booth, D. A. (1989). Dependence of carbohydrate-conditioned flavour preference on internal state in rats. Learning and Motivation 20, 36-47.

Greenhalgh, J. F. D. \& Reid, G. W. (1971). Relative palatability to sheep of straw, hay and dried grass. British Journal of Nutrition 26, 107-116.

Grovum, W. L. (1988). Appetite, palatability and control of feed intake. In The Ruminant Animal, pp. 202-216 [D. C. Church, editor]. Englewood Cliffs: Prentice Hall.

Kikuzaki, H. \& Nakatani, N. (1989). Structure of a new antioxidative phenolic acid from oregano (Origanum vulgare L.). Agriciculture and Biological Chemistry 53, 519-524.

Leibowitz, S. F. (1988). Opioid, $\alpha 2$-noradrenergic and adrenocorticotropin systems of hypothalamic paraventricular nucleus. In Perspectives in Behavioral Medicine. Eating Regulation and Discontrol, pp. 113-131 [H. Weiner and A. Baum, editors]. Hillsdale, NJ: Lawrence Erlbaum Associates.

Mehiel, R. (1991). Hedonic-shift conditioning with calories. In The Hedonics of Taste, pp. 107-126 [R. C. Bolles, editor]. Hillsdale, NJ: Lawrence Erlbaum Associates.

Mook, D. G. (1988). On the organization of satiety. Appetite 11, 27-39.

Nakatani, N. \& Kikuzaki, H. (1987). A new antioxidative glucoside isolated from oregano. Agriculture and Biological Chemistry 51, 2727-2732.

National Research Council (1985). Nutrient Requirements of Sheep. Washington, DC: National Academy Press.

Perez, C., Lucas, F. \& Sclafani, A. (1995). Carbohydrate, fat, and protein condition similar flavour preferences in rats using an oral-delay procedure. Physiology and Behavior 57, 549-554.

Provenza, F. D. (1995a). Postingestive feedback as an elementary determinant of food preference and intake in ruminants. Journal of Range Management 48, 2-17.

Provenza, F. D. (1995b). Role of learning in food preferences of ruminants: Greenhalgh and Reid revisited. In Ruminant Physiology: Digestion, Metabolism, Growth and Reproduction. Proceedings VIII International Symposium on Ruminant Physiology, pp. 231-245. Stuttgart: Ferdinand Enke Verlag.

Provenza, F. D. (1996a). Acquired aversions as the basis for varied diets of ruminants foraging on rangelands. Joumal of Animal Science 74, 2010-2020.

Provenza, F. D. (1996b). A functional explanation for palatability. In Proceedings V International Rangeland Congress pp. 123-125 [N. E. West, editor]. Denver, CO: Society for Range Management.

Provenza, F. D., Scott, C. B., Phy, T. S. \& Lynch, J. J. (1996). Intake by sheep of foods varying in flavours and nutrients. Journal of Animal Science (In the Press).

Ralphs, M. H., Provenza, F. D., Wiedmeier, W. D. \& Bunderson, F. B. (1995). The effects of energy source and food flavour on conditioned preferences in sheep. Journal of Animal Science 73, 1651-1657. 
Salmeron, J., Jordano, R. \& Pozo, R. (1990). Antimycotic and antiflatoxigenic activity of oregano (Origanum vulgare, L.) and thyme (Thymus vulgaris, L. ). Journal of Food Protection 53, 697-700.

Sclafani, A. (1991). Conditioned food preferences. Bulletin of the Psychonometric Society 29, $256-260$.

Sclafani, A. \& Nissenbaum, J. W. (1988). Robust conditioned flavour preference produced by intragastric starch infusions in rats. American Journal of Physiology 255, R672-R675.

Swithers, S. E. \& Hall, W. G. (1994). Does oral experience terminate ingestion? Appetite 23, 113-138.

Van Soest, P. J. (1994). Nutritional Ecology of the Ruminant. New York: Cornell University Press.

Villalba, J. J. \& Provenza, F. D. (1996). Preference for wheat straw by lambs conditioned with intraruminal administrations of sodium propionate. Journal of Animal Science 74, 2362-2368.

Wang, J. \& Provenza, F. D. (1996). Food preference and acceptance of novel foods by lambs depend on the composition of the basal diet. Journal of Animal Science 74, 2349-2354.

Westoby, M. (1978). What are the biological bases of varied diets? American Naturalist 112, 627-631.

Wiedmeier, R. D., Arambell, M. J. \& Walters, J. L. (1987). Effect of orally administered pilocarpine on ruminal characteristics and nutrient digestibility in cattle. Journal of Dairy Science 70, 284-289.

Wurtman, R. J. \& Wurtman, J. J. (1986). Carbohydrate craving, obesity and brain serotonin. Appetite 7, Suppl., 99-103.

Zahorik, D. M. \& Houpt, K. A. (1977). The concept of nutritional wisdom: applicability of laboratory learning models to large herbivores. In Learning Mechanisms in Food Selection, pp. 45-67 [L. M. Barker, M. Best and F. Domjan, editors]. Waco, TX: Baylor University Press. 